\title{
THREE-DIMENSIONAL (3D) EQUILIBRIUM ANALYSIS OF GOTHIC MASONRY VAULTS
}

\author{
Philippe Block and Lorenz Lachauer \\ ETH Zurich, Institute of Technology in Architecture, Zurich, Switzerland
}

This study presents a practical method for three-dimensional static equilibrium analysis for masonry vaults using funicular networks. The method, a nonlinear extension of Thrust Network Analysis, is explained, and through three exemplary case studies, the potential of this new research is demonstrated. These examples discuss different assumptions on the "flow of forces" in Gothic quadripartite vaults; visualize the flat-vault equilibrium of rose windows under wind loading; and provide a stability analysis of the intricate nave vaults of Sherborne Abbey, Dorset, England. The presented approach provides insights in structural redundancy of unreinforced masonry structures by quantifying lower bounds on the geometric safety factors. The method for efficient funicular analysis of complex vault geometries furthermore provides the foundation for a fully three-dimensional funicular analysis implementation, extending thrust line analysis to three-dimensional thrust networks, for historic masonry.

KEY WORDS: unreinforced masonry structures, Gothic vaults, Gothic rose windows, flow of forces, equilibrium analysis, limit analysis, funicular analysis, thrust network analysis, geometric safety factor

\section{INTRODUCTION}

Unreinforced masonry structures generally fail not due to lack of compressive strength, but due to instability (Heyman 1995; Ochsendorf 2002). Understanding the equilibrium of structures in masonry is thus of primary concern. The importance of equilibrium methods for the analysis of masonry structure, framed in an extensive historical overview, is provided and argued very clearly by Huerta $(2001,2004,2008)$. To determine the stability, and hence to assess the safety of masonry structures, limit analysis provides a useful theoretical framework (Kooharian 1962; Heyman 1966).

\subsection{Limit Analysis of Masonry Structures}

In the classic limit analysis framework, the safe theorem states that, under certain assumptions such as no sliding at the masonry interfaces, infinite compressive strength of the masonry, which combines a static (sufficient resistance) and a kinematic aspect (no

Received January 7, 2013; accepted June 11, 2013.

Address correspondence to Philippe Block, ETH Zurich, Institute of Technology in Architecture, 15 Wolfgang-Pauli-Strasse, Zurich 8003, Switzerland. E-mail: block@ arch.ethz.ch 
deformation), and no tensile capacity, it is sufficient to find one possible equilibrium state in compression for the structure under the applied loads, to guarantee safety (Heyman 1995). In two dimensions, such equilibrium can be found and visualized by constructing a thrust line that fits within the geometry of the structure. In practice, one wants to constrain the solution rather to a particular zone of the structure's section, for example $0,85 \cdot d$, with $d$ the depth of the section, to account for imperfections in the real geometry, but also to avoid unrealistic stress concentrations, which would violate the no-crushing assumption (Heyman 1995) Thrust line analysis is a useful tool to explain and examine the stability of two-dimensional (2D) structures, but unfortunately practically limited to them. They have been used though to perform pseudo-three-dimensional (3D) analyses (Wittmann 1879; Wolfe 1921; Block et al. 2006a), which often produce overly conservative results.

In support of this analysis framework, Holzer (2012) showed recently very clearly that the ultimate load capacity of an arch is perfectly approximated using "thrust zone" analysis, which is a concept that extends thrust line analysis by adding geometric constraints that account for the limited compressive strength of the material (Durand-Claye, 1867, 1880; Smith, Harvey, and Vardy 1990). Holzer showed that at collapse the results of this fast limit analysis approach are practically identical to the solution obtained with an iterative, nonlinear finite element implementation.

Boothby (2001) provided a critical overview of the different analysis methods for masonry arches and vaults, and calls for the development of an automated 3D version of graphical equilibrium analysis; a call, which was echoed by Kurrer (2008).

We also refer to Roca et al. (2010) for an exhaustive and general overview of the state of the art of approaches for structural analysis of historic masonry constructions.

\subsection{D Funicular Analysis of Masonry Vaults}

In order to extend thrust line analysis to spatial structures, O'Dwyer (1999) introduced the use of 3D funicular force networks defined in plan. Using optimization, compression-only networks that are in equilibrium with both self-weight and applied loads, and fit within the geometry of the structure, could be obtained. By limiting the problem to vertical loading, and by keeping the layout of the networks fixed in plan during the solving, the nodal heights could be solved through an iterative routine with linear optimization at each step. O'Dwyer's research showed the important influence the topology of the chosen networks has on the obtainable equilibrium solutions, and introduced the mathematical formulations of different objective functions relevant to the assessment of masonry (Section 1.3). Even though the fixed network in plan still inherently renders conservative results, these 3D networks give a much better understanding of vaults than the simplified analysis that combine two-dimensional thrust line analyses.

An important limitation of this method though was the lack of a general approach to deal with the static indeterminacies in the horizontal equilibrium of networks with a fixed horizontal projection. This horizontal equilibrium needed to be known to be able to linearize the problem. As the solving depended on providing thrust values to all edges, applications were thus limited to simple, often symmetric networks, for which the thrusts could be calculated through careful inspection of the chosen network topology. And because the dependencies of the thrust values were not formalized in O'Dwyer's (1999) approach, these variables could not be included in the optimization problem. A second issue was that not every choice of horizontal equilibrium necessarily resulted in an equilibrium solution fitting the solution space, the vault's section. 
Building on O'Dwyer's seminal work, thrust network analysis (TNA) addressed the first issue by introducing reciprocal force diagrams (Maxwell 1864), which describe the possible horizontal equilibria of compressive funicular networks, named thrust networks, under vertical loading (Block and Ochsendorf, 2007, 2008; Block, 2009).

These allowed the analyst to calculate, visualize and explicitly control the horizontal equilibrium, and hence the degrees of indeterminacy of thrust networks. Using the geometrical information provided by these diagrams, TNA provided a general framework for linearizing O'Dwyer's equations of equilibrium for any topology of network by providing equilibrated thrusts for all edges of the network. TNA furthermore adopted the data structure and matrix formulation of the force density formulation (Schek 1974), which improved the solving speed by several orders of magnitude over the node-wise approach.

An important drawback of the original TNA framework, as presented in the abovementioned references, though was the lack of a general algorithm to automatically identify, control, or vary the degrees of indeterminacy of the horizontal equilibrium of thrust networks with fixed projection. The manual manipulation of the reciprocal force diagrams - each possible force diagram corresponds to a 3D thrust network for the given loads and boundary/support conditions-guaranteed that all solutions where in compression, but was of course not sufficient to find specific equilibrium solutions, for example one that fits in thin masonry vaulted structures with complex geometry. This paper will present the extensions to TNA that overcome this constraint.

Another recent approach for 3D limit analysis based on funicular networks has been proposed by Andreu, Gil, and Roca $(2007,2010)$. An important difference to the approach presented in this paper is that, although easily general loading cases could be included, the equilibrium solutions are not constrained to fixed horizontal projections, which will be argued in this discussion to be of particular practical importance for masonry assessment. A related approach to TNA for generating funicular networks for vertical loading cases has been proposed by Fraternali (Fraternali and Rocchetta, 2002; Fraternali, 2010), as a specific 3D extension of the lumped stress method (Fraternali, Angelillo, and Fortunato 2002). Block (2009) has showed that their equilibrium conditions and global framework, separating horizontal and vertical equilibrium, was entirely equivalent to TNA, but in contrast, this approach, based on discretized airy stress functions, had challenges with respect to singularities in the boundary conditions and loading, or discontinuities, such as cracks or openings, in the discretized equilibrium surfaces and the supports. Recently, the mathematical foundation of this framework, based on TNA and the lumped stress method, has been formalized and extended with efficient solving algorithms by Vouga et al. (2012) to find particular best-fit solutions to target surfaces, but because their solving strategy was not based on fixed pattern layouts, their method is unable to capture typical sharp features of Gothic masonry vaults, such as creases along ribs. Convergence issues also remain.

\subsection{Problem Statement}

Although it is sufficient, based on the safe theorem, to find a possible compressive equilibrium state for the vault, or in geometrical terms, a possible thrust network that stays within the vault's geometry, it is useful to identify specific equilibrium solutions, e.g. associated to the following objectives:

- Maximizing the ratio between the thinnest possible vault geometry enveloping a funicular solution in equilibrium with given loads over the actual vault geometry, which 


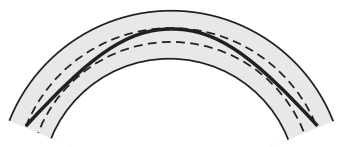

(a)

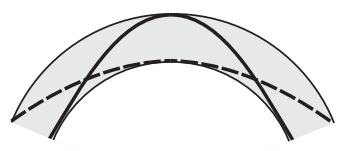

(b)

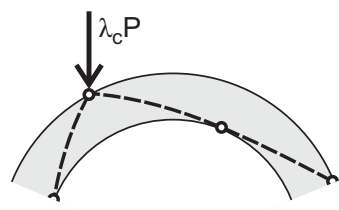

(c)

Figure 1. Illustration of different relevant specific funicular solutions for an arch, providing (a) the geometric safety factor, (b) the minimum and maximum thrust, and (c) the collapse load factor for a given live load location.

renders the geometric safety factor (GSF) (Heyman 1982; O’Dwyer 1999), a measure of the closeness to collapse of the vault under those loads (Figure 1a).

- Minimizing/maximizing horizontal thrust, which provides the thrust values that bound the range of thrust that the vault will and can exert onto its neighboring elements (Figure 1b).

- Maximizing the collapse load factor, which indicates how much live load a vault can take before a collapse mechanism is formed, i.e., the thrust line no longer fits inside of the vault (Figure 1c).

In $2 \mathrm{D}$, there is furthermore a direct relation between the thrust lines in Figures $1 \mathrm{~b}-1 \mathrm{c}$ and the collapse mechanisms: Where the lines touch the intrados and extrados on alternate sides, hinges will form (Heyman 1995). It has not been shown that such a relation exist for vaults.

This study will focus on finding the thrust network with a given plan layout that maps the mid (or other target) surface of the vault. This objective is chosen because it fulfils the main objective of finding a safe field of admissible stress, represented by that thrust network that stays within a defined portion of the section of the vault. It can furthermore be solved very efficiently and fast, which means that many analyses under different force pattern assumptions can be ran and tested consecutively. Also, the obtained solution provides a good lower bound on the geometric safety factor (GSF) of the vault for a given loading (although the quality of the lower bound will depend on the choice of network topology). Lastly, the resulting best-fit solution forms the basis for finding other objectives, such as the ones shown in Figure 1, by providing a good and feasible starting point for the respective optimization problems. Currently, the algorithms consider perfect geometry, thus not taking displacements or structural pathologies into account, which will be addressed in future research (see Section 5).

A particular objective of this study is to demonstrate that the new nonlinear search algorithms, presented in Block and Lachauer (2011) or in Panozzo, Block, and SorkineHornung (2013) and Van Mele et al. (2014), are the foundation for a flexible, intuitive, fast and robust, and thus practical, equilibrium analysis implementation for assessing vaulted masonry. This aim directly responds to the needs and demands from practice where leading masonry experts still extensively use thrust line analysis as a key part of the stability and safety assessment of historic masonry structures, partly also influenced by time and budget restraints. The new algorithms for the TNA framework constitute an important step to develop software implementations that provide this practical limit analysis framework for fully $3 \mathrm{D}$ problems, as will be shown in this paper through several examples from the field of structural assessment of historic structures. 
The method facilitates understanding how thin vaults with double curvature can be stable, but the main advantage of the extended TNA is that it is faster and easier to investigate complex networks. For this, two important assumptions are added to Heyman's assumptions in Section 1.1: As in thrust line analysis, possible spatial flow of forces are modeled using linear elements, arranged following some a priori specified topology, and loading is limited to vertical, or parallel loading. The first assumption unavoidably renders unconservative results compared to more general approach that model vaults as surfaces, volumes or blocks, as there is a strong influence on how the structure is modeled and disretized. But, because of the extremely fast computation, thanks to the new solving algorithms, the analyst gets practically real-time feedback for each force pattern drawn or generated, which allows him to check many force flow assumptions rapidly, e.g., considering information from a visual assessment of the vault, such as crack locations.

\section{THRUST NETWORK ANALYSIS}

This section will give a short review of the concepts and assumptions of the Thrust Network Analysis framework, and identify the necessary extensions. TNA is an analysis approach that allows performing funicular analysis using discrete networks and under parallel loading conditions, giving a very high degree of control to the analyst to explore different assumptions on the force flow in vaulted masonry.

\subsection{Equilibrium of Thrust Networks}

For the static analysis of (historic) masonry vaults, which typically have a heavy, dominant self-weight, it is sufficient to consider vertical loading only. For gravity loading, the lines of action of the loads are vertical, and it is thus meaningful to keep the horizontal projection of the laid-out network fixed during the analysis process. This is equivalent in 2D to thrust line analysis, done using graphic statics, where indeed the nodes in the funicular form stay on the verticals through the centroids of single stones, called voussoirs, of a masonry arch (Block et al. 2006a). Live loads are also applied at specific $(x, y)$-locations, and thus also want to stay fixed during the analysis. Lastly, the location of cracks and openings are hard constraints on the analysis, as no thrust can travel across them, something other approaches have challenges with. Note that the TNA framework requires parallel loading cases, of which vertical loads represent a special case (Block 2009).

The vertical equilibrium of a typical node $i$ in a thrust network (Figure 2a) is given by Equation 1:

$$
F_{V, j i}+F_{V, k i}+F_{V, l i}=P_{i}
$$

in which $F_{V, j i}$ are the vertical components of forces in edges $j i$, and $P_{i}$ is the load applied at node $i$.

When rewriting the vertical equilibrium equations (1) in function of the horizontal force components, i.e., the thrusts, $F_{H, j i}$, using Equation 2:

$$
F_{V, j i}=F_{H, j i} \cdot \tan \left(\alpha_{j i}\right)=F_{H, j i} \cdot \frac{z_{i}-z_{j}}{l_{H, j i}}
$$

one gets after rearranging: 


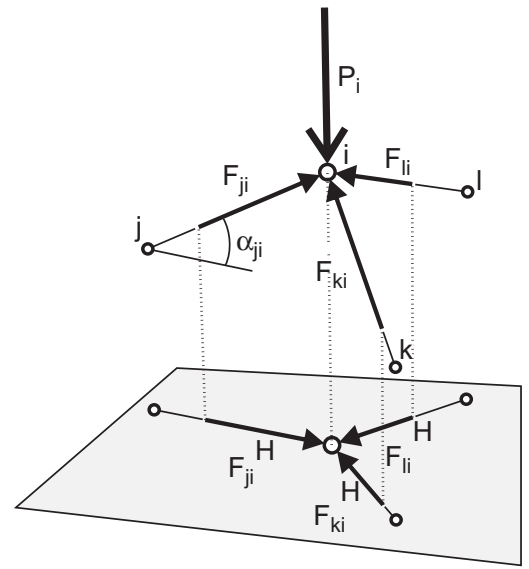

(a)

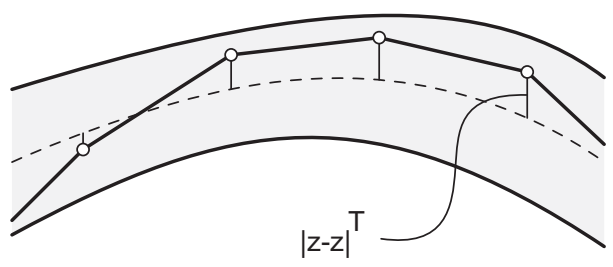

(b)

Figure 2. Illustration of (a) a typical node $i$ in the thrust network with applied load $P_{i}$ and branch forces $F_{j i}$, and (b) the height deviation $\left|z-z^{\mathrm{T}}\right|$ of the thrust network from the target surface of the vault.

$$
\left(\frac{F_{H, j i}}{l_{H, j i}}+\frac{F_{H, k i}}{l_{H, k i}}+\frac{F_{H, l i}}{l_{H, l i}}\right) z_{i}-\frac{F_{H, j i}}{l_{H, j i}} z_{j}-\frac{F_{H, k i}}{l_{H, k i}} z_{k}-\frac{F_{H, l i}}{l_{H, l i}} z_{l}=P_{i}
$$

in which $l_{H, j i}$ are the horizontal lengths of edges $j i$, which is exactly the problem that is being solved in O'Dwyer (1999). These equations can be linearized by providing values for $F_{H, j i}$, which for a given horizontal projection are not independent; they need to be chosen such that they represent a possible horizontal equilibrium with the fixed plan geometry. This requirement can be guaranteed by constructing allowed compressive reciprocal force diagrams, which is one of the core premises of TNA (Block 2009; Van Mele et al. 2012). These force diagrams furthermore allow to linearize Equation (3) by measuring the lengths of the corresponding reciprocal edges, $l^{*}{ }_{H, j i}$, which are the (scaled) magnitudes of the thrusts $F_{H, j i}$ as shown in Equation 4:

$$
q_{j i}=\frac{F_{H, j i}}{l_{H, j i}}=\frac{l_{H, j i}^{*}}{l_{H, j i}}
$$

with $q_{j i}$ the well-known force densities (Schek 1974) or tension coefficients (Pellegrino and Calladine 1986).

\subsection{Controlling the Indeterminacy of Thrust Networks}

For 3D networks, obtaining one of the specific equilibrium solutions in Section 1.3 is not a straightforward task because of the high degree of static indeterminacy of such models. Put simply, rather than having one horizontal thrust to consider, as for planar structures, such as arches on buttresses, these networks have highly dependent combinations of horizontal thrusts in their edges (Block 2009). This is clarified and visualized in TNA with reciprocal force diagrams, which represent the different possible horizontal equilibria of these networks for given form diagram (Figure 3). 


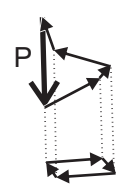

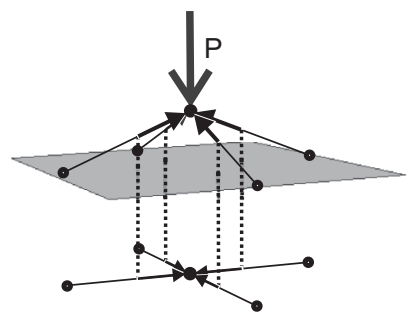

(a)

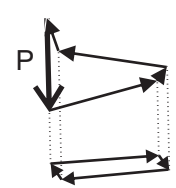

(b)

Figure 3. Illustration of several static equilibrium states existing for determinate networks: for the same load $P$, form diagram, and overall depth of the solution, but when changes in the force diagram, i.e., changes in the internal distributions of thrusts, several thrust networks result. The force diagram of (b) is stretched to double the size in one direction compared to (a), resulting in the doubling of the horizontal forces in that direction and therefore also in a thrust network half as deep in that direction.

For a single node or simple networks, describing the dependencies between the thrusts for form diagrams that stay fixed in the horizontal plane, is still manageable, but the complexity of the problem grows quickly for large networks with arbitrary topology. A strategy is thus needed to:

1. understand the dependencies between the thrusts in the different edges of the network, i.e. how local changes in thrust influence the thrusts globally, while keeping the projection of the solutions fixed; and

2. develop control mechanisms to produce different equilibrated thrust distributions to search for one of the specific lower-bound equilibrium solutions in Figure 1.

\section{COMPUTATIONAL IMPLEMENTATION}

This section will outline the key steps of the nonlinear extensions of TNA that address the challenges posed above. Controlling the dependencies has been solved algebraically in Block and Lachauer (2011), and explicitly in Panozzo et al. (2013) and Van Mele et al. (2014).

\subsection{Nonlinear-Solving Approach}

As mentioned earlier, addressing the second challenge in Section 2.2, this paper will be searching for the "best-fit" solution that minimizes in a least-squares sense the vertical deviations between the solution and the target surface defined inside of the vault (Figure 2b), as shown in Equation 5:

$$
f(\mathbf{q})=\left\|z-z^{T}\right\|^{2}
$$

with $\mathbf{z}$ the thrust network, and $\mathbf{z}^{\mathrm{T}}$ the target surface.

A specific case for the target surface is when $\mathbf{z}^{\mathrm{T}}=\mathbf{z}^{\mathrm{M}}=\left(\mathbf{z}^{\mathrm{I}}+\mathbf{z}^{\mathrm{E}}\right) / 2$, with $\mathbf{z}^{\mathrm{I}}$ and $\mathbf{z}^{\mathrm{E}}$ the intrados and extrados heights of the vault respectively, which thus coincides with the mid surface of the vault. The best-fit solution, found with the objective function (5), 
represents a lower bound on the geometric safety factor (Figure 1.a), and dependent on the topology of the force pattern chosen, it will generate a lower bound more or less close to the GSF. This objective is chosen because this least-squares problem can be solved very efficiently, and because the resulting solution forms a good and feasible starting point for finding the objectives in Section 1.3: finding the minimum versus maximum thrust networks of the vault (Figure 1b) or obtaining the geometric safety or collapse load factors for a given loading case (Figure 1a and 1c).

Minimizing the objective function (5) is a difficult nonlinear optimization problem (Vouga et al., 2012). The nonlinear relationship between $\mathbf{z}$ and $\mathbf{q}$ is clear from the equilibrium Equations (3). Two strategies to solve the problem have been proposed, and will be summarized next. For a detailed description of the mathematical formulations and algorithms, the authors refer to the provided references.

The first, algebraic approach (Block and Lachauer 2011, 2013) introduces a method for identifying the thrust dependencies between edges in equilibrium networks with parallel loads and fixed projection, based on matrix analysis of structural frames. The main concept is that, because only vertical loads are considered, each in-plane equilibrium of the (unloaded) 2D bar-node structure that coincides with the projection on the plane of the thrust network, represents a possible horizontal equilibrium of a funicular network for the given loads. These equilibria correspond to the states of self-stress of that planar structure, and identifying these, give the independent edges of the network, i.e. the edges whose thrusts, or equivalently force densities $\mathbf{q}_{\text {indep }}$, can be chosen freely without violating the equilibrium of the fixed planar network topology. This approach particularly gives clear insights into the dependencies of the variables of the problem.

The second, explicit approach (Panozzo et al., 2013; Van Mele et al., 2014) improves the robustness of the search algorithms and particularly also increases the speed of solving over the first, algebraic approach, by searching over all force densities q. In this method, it is guaranteed that all thrust distributions represent possible compressive equilibria for the fixed projection by explicitly controlling both form and force diagram. The efficiency of this approach comes from sampling the best components of previous research: the robust, iterative algorithms for guaranteeing equilibrium developed in Rippmann Lachauer, and Block(2012a), which allow to deal with imperfect form diagrams (see Section 4.2.2), the analytically provided best-fit objective function and gradient, and efficient search algorithm used in Van Mele and Block (2011).

\subsection{Overview Implementation}

This section provides an overview of the main steps of the workflow of the current implementation, which is intended as a prototype for new 3D limit analysis tools for complex vaulted masonry. Figure 4 shows schematically what is needed as input (left) and what is generated as output (right), and Figure 5 shows a pipeline of the computational implementation. The dotted steps are either optional or are only necessary in particular solvers (Section 3.1).

From the intrados and extrados surfaces, $S^{\mathrm{I}}$ and $S^{\mathrm{E}}$ respectively, of the vault, which can be generated from a point cloud from a laser-scan survey, the self-weight loading is computed. The target surface $S^{\mathrm{T}}$ can either be generated as mid surface of the vault, defined by the intrados and extrados, or directly provided by the analyst. This allows the analyst, for example, to constrain the solution to stay within certain parts of the masonry, e.g. in the ashlar masonry shell, rather than going through rubble infill. 

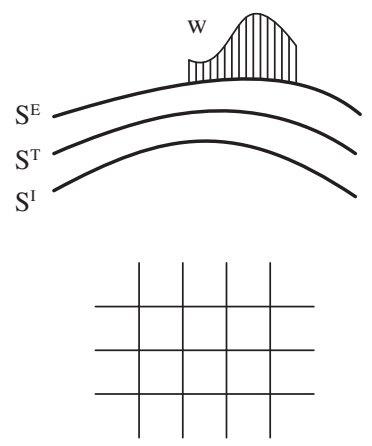

$\Gamma$
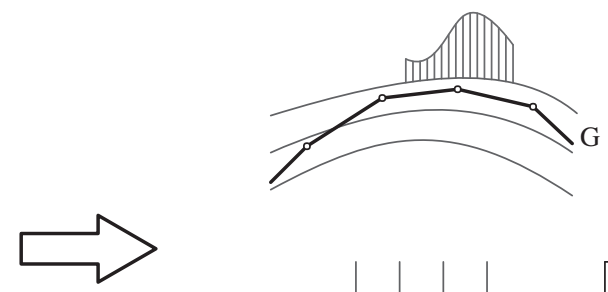

$\Gamma$

$\Gamma^{*}$

Figure 4. Illustration of the main inputs of the current implementation (left): optionally, the vault's intrados and extrados surfaces, $S^{\mathrm{I}}$ and $S^{\mathrm{E}}$; the target surface, $S^{\mathrm{T}}$; additional surcharge loading w; and the force layout as form diagram $\Gamma$. Overview of the main outputs (right): the best-fit thrust network G, and the (scaled) force diagram $\Gamma^{*}$ corresponding to that equilibrium solution.

Additional surcharges $\mathbf{w}$ can be added, which, together with the self-weight components, make up the loads $\mathbf{p}$ that are lumped, based on their tributary area, to the appropriate nodes of the network, defined by the two-dimensional form diagram $\Gamma$. This force pattern is laid out on the horizontal plane, and is the horizontal projection of the to-be-found 3D thrust network. The form diagram $\Gamma$ can either be drawn by the analyst or generated e.g. with the algorithms in Panozzo et al. (2013).

After generating a starting point, the optimization problem to minimize (Equation 5) is done iteratively using a gradient $\nabla f$. The implementation produces as geometric output the best-fit thrust network $\mathrm{G}$ and the reciprocal force diagram $\Gamma^{*}$. From these, all forces in the network are known, which are then used to check stresses and friction thresholds at the voussoirs' interfaces. Different visualizations will be used in Section 4 to better represent the results.

\section{APPLICATIONS}

This section will present case studies illustrating the method. In Section 4.1 different assumptions of force patterns for quadripartite vaults are compared on a generic vault geometry, adding to the historical debate on the flow of forces in Gothic vaults; in Section 4.2, the flat-vault action of several, intricate rose windows is explored; and in Section 4.3, the nave vaults of Sherborne Abbey, England are used as case study of an equilibrium analysis of a structural rib network with complex geometry.

\subsection{Flow of Forces in a Quadripartite Vault}

An important aspect for the analysis of masonry vaults using thrust networks is to define an appropriate form diagram to model a plausible flow of forces in a 3D structure. Because of the setup, that the horizontal projection of all equilibrium solutions is kept fixed, different network topologies can be easily compared to obtain better insights into the 
Input

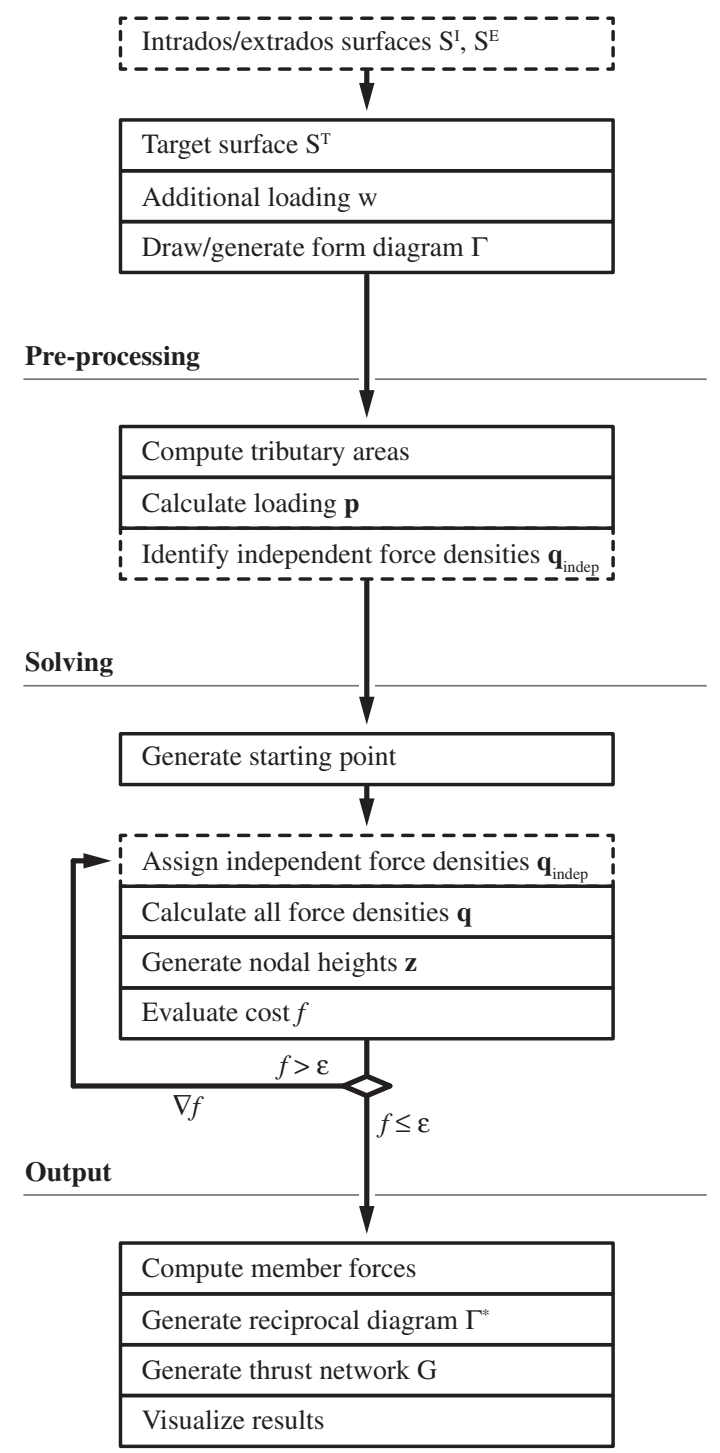

Figure 5. Diagram of the steps of the computational implementation, divided into input, pre-processing, solving and output.

structural logic of certain masonry vault geometries, and thanks to the newly developed efficient solvers, equilibrium solutions can now be generated practically instantaneously. This explicit control allows thus to fully understand the different possible lower-bound equilibria of vaulted structures under different assumptions. There has been extensive debate on the structural behavior of masonry vaults, with a particular emphasis on the perceived role of the rib in Gothic vaults (Viollet-le-Duc 1854; Sabouret 1928; Abraham 1934; Heyman 1968; Mark, Abel, and O’Neill 1973). 
Many scholars have assumed that the vault forces "flow" to the supports in the same manner as water would drain off the vault's upper surface or as a cannonball would roll off the extrados of a vault, as Abraham (1934) claimed (Figure 6a), correcting Viollet-leDuc's "wrong" ' assumption on how the forces would travel to the supports (Viollet-leDuc, 1854) (Figure 6b). Following a similar logic, Ungewitter and Mohrmann (Ungewitter, 1890) and Rave (1939) defined that a reasonable slicing of a vault, needed for a pseudo-3D discretization of the force paths in masonry vaults, is to cut them up according to lines of steepest descent (Figure 6c). This assumption is perfectly reasonable for properly supported vaults or shells, and has strong correspondances with Heyman's explanation that Gothic vaults act as thin shells with stress concentrations along creases (Heyman 1977, 1995), as it is known that there is a direct relation between curvature and membrane stresses in shells (Calladine 1983). For non-properly supported vaults though, these assumptions no longer make sense. For example, in the case of the often occurring Sabouret cracks, which run parallel and along the sides of a quadripartite vault (Sabouret 1928; Heyman 1995), these cracked boundaries cannot transfer thrust.

In that situation, a curvature analysis of the vault's geometry could result in thrusts hitting these unsupported edges (as would be the case for the vault geometry shown in Figure 7). Instead, forces should have been redirected to run parallel along those unsupported edges towards the supported corners. It is clear that other approaches are needed, and that we need to get rid of the common misconception to use a curvature analysis to decide on the discretization. Panozzo et al. (2013) address this issue, and propose an optimization framework to automatically generate appropriate force patterns for self-weight

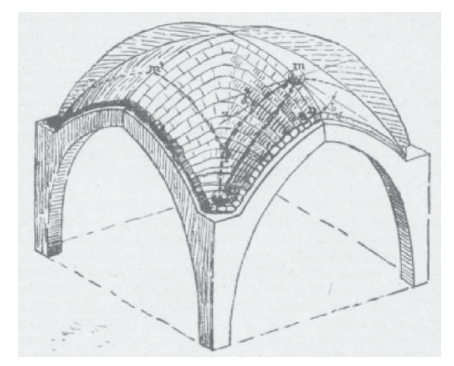

(a)

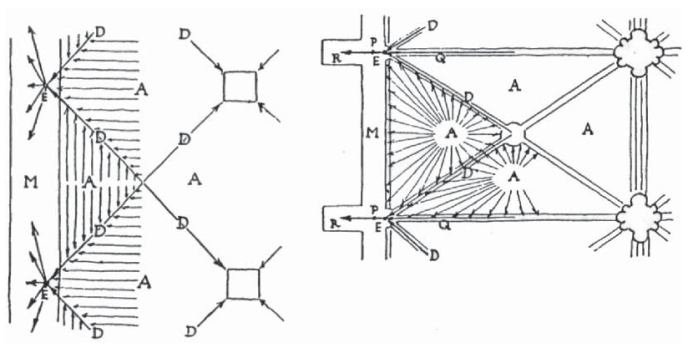

(c)

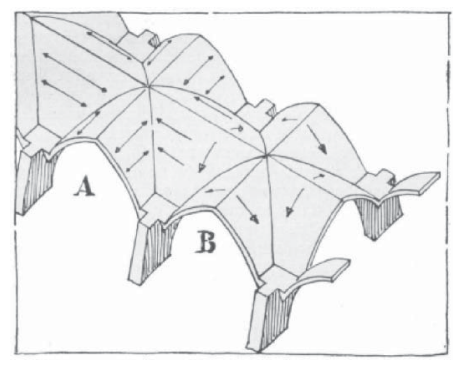

(b)

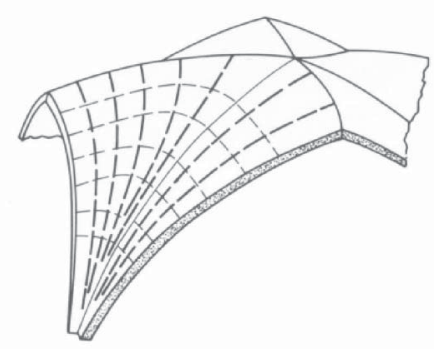

(d)

Figure 6. Illustration of different assumptions on how the forces flow to the supports in a quadripartite vault, according to (a) Abraham (1934), (b) Viollet-le-Duc in part A (Abraham, 1934), (c) Rave (1939), and (d) Mark (1982). 


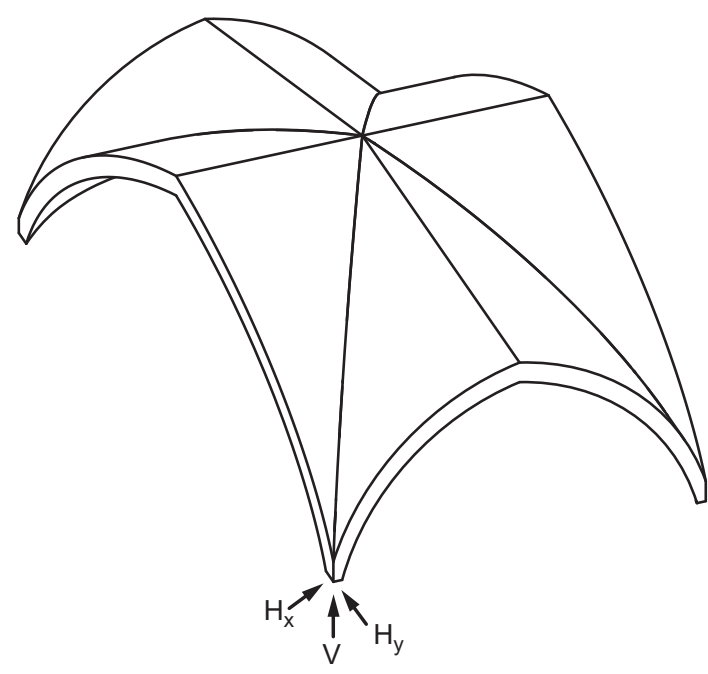

(a)

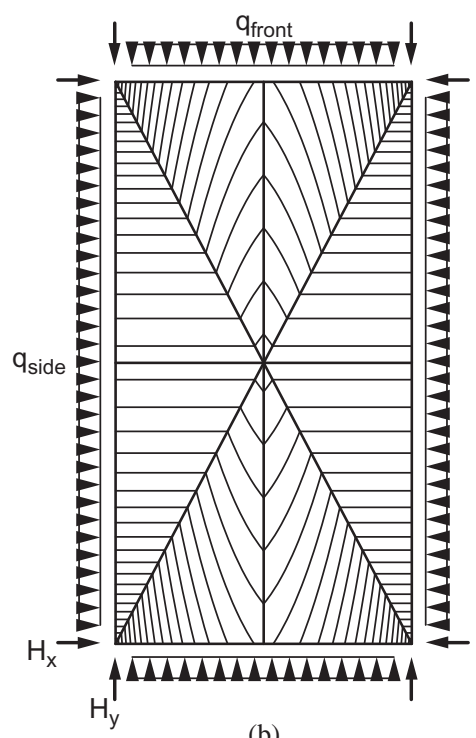

(b)

Figure 7. Illustrated example of generic quadripartite vault geometry with dimentions $13 \mathrm{~m} \times 7 \mathrm{~m} \times 4.5 \mathrm{~m}$ : (a) axonometry, and (b) top view, with height contour lines, horizontal thrust at the corners in both $\mathrm{x}$ - and y-direction. As conservative assumption it is assumed, that the boundary thrust at the edges $\mathrm{q}_{\text {side }}$ and $\mathrm{q}_{\text {front }}$ is zero.

by applying structural heuristics (e.g., force lines should trace sharp features, such as creases in the vault's surface along a rib, or should not hit unsupported boundaries [e.g., of openings]) to generate more informed topologies based on the vault's geometry. This research considered only perfect geometry, but could be extended to include structural pathologies.

This issue is also particularly clear when including point loads. Even if perfectly supported, the patterns generated from a curvature analysis can only be considered as reasonable assumptions to represent the self-weight, as they do not necessarily include the "ideal" load paths to carry the live loads to the supports. O'Dwyer (1999) proposed that a good discretization should combine, or at least reflect all possible ways the forces in the vault could act. It has been clearly shown by O'Dwyer (1999), and Van Mele et al. (2014) that overlays of the patterns for the dead and live loads result in significantly less conservative assessments, and more importantly, that the dead load pattern not always allows finding an equilibrium solution for the combined loading case, i.e. a solution that stays within the section of the vault.

The most important information to decide on force pattern layouts is obtained by looking for pathological information in-situ (e.g., cracks, deformations, fallen-out stones/bricks). The network approach allows including those naturally, for example, by taking out branches, such that no compressive forces run through cracked areas. The fixed horizontal projection guarantees that such impossible force flows do not occur during the nonlinear search. Other important hints on force layouts are provided by experimental research (e.g., Barthel, 1994; Jagfeld and Barthel, 2004).

These issues are not considered in the theoretical example in this section; perfect, non-cracked geometry will be assumed, as well as perfectly rigid foundations (i.e., no support discplacements). 
Mark et al. (1973) used photo-elastic analysis on carefully machined, perfectly homogeneous and smooth, plastic models to show the path of forces in a groin vault (Figure 6d). This is thus equivalent to doing a linear elastic FE analysis, hence assuming a continuous, homogeneous body and furthermore only considering "perfect world" boundary conditions, to explain the stability of the discrete masonry vault. Next to the fact that the solution will be significantly influenced by the significant tensile capacity of the plastic model, the result does not acknowledge the indeterminacy of the problem, i.e. it generates one, fictional lower-bound solution, based on erroneous boundary conditions and parameters.

Barthel (1994) studied the force paths in Gothic vaults using nonlinear FEM analysis, hence not erroneously including the fictional tensile capacities of cracked masonry, but also provided a very clear state-of-the-art report and discussion of the different discretizations proposed historically for several vault geometries. Particularly his categorization of typical observed crack patterns unveiled important clues to explaining the flow of forces in vaults of different geometry. Heyman (1995) indeed also already discussed this aspect. In many churches, one observes the combination of Sabouret cracks and cracks running along the center of the nave. It can thus be concluded that these vaults globally act as three-hinged arches, thus effectively as barrel vaults. Holzer (2012) showed the validity of this model quantitatively by comparing the resulting thrusts at the abutments for several pseudo-3D discretizations that were based on different kinematically admissible crack patterns, which he repeatedly observed in practice. These were lastly benchmarked by a top-level analysis considering the groin vault as simple barrel vault, showing only marginal difference for all assumptions.

It is clear that there has been a long-lasting discussion on how Gothic vaults "exactly" work. Of course, these discussions always need to be framed correctly, particularly that the question differs heavily for each specific case study. This section shows that the method presented in this study allows for a systematic comparison of different assumptions on the force flow of vaults. These are all of course possible equilibrium solutions for the statically highly indeterminate problem, but thanks to the new algorithms, the different assumptions on the force paths can be evaluated and discussed using quantifiable measures, for example by comparing how well the funicular solutions generated from each force pattern map in a least-squares manner to a given vault's mid surface.

As an example, this section will look at different possible layout of forces for the generic quadripartite vault geometry shown in Figure 7, which was constructed following Fitchen's geometrical diagrams (Fitchen 1961). It can be seen from the height contour lines (Figure $7 \mathrm{~b}$ ) that the intersecting pointed vault section spanning the $\mathrm{x}$-direction has only single curvature (parallel isolines) and that the other is doubly curved (curved isolines).

Figure 8 shows in the top row the best-fit thrust networks for five different layouts (a-e). The pipes around the edges of the thrust networks are proportional to the magnitude of force in them. The chosen form diagrams are shown in the middle row, with circles over each node proportional to the vertical deviation of the node in the best-fit thrust network work, measured with respect to the target surface, taken as mid surface of the vault. The bottom row shows the reciprocal force diagrams, corresponding to the respective best-fit solutions for the five patterns and drawn to the same scale. These show the equilibrium and distribution of horizontal thrusts in the equilibrium solutions.

The patterns have been defined such that they interpret and represent the different assumptions posed in the historical debate, and only have thrust components at the corners. This would mean that the sidewalls do not take any thrust, which, for example, could account for the typically observed Sabouret cracks along the sides of a quadripartite vault. 


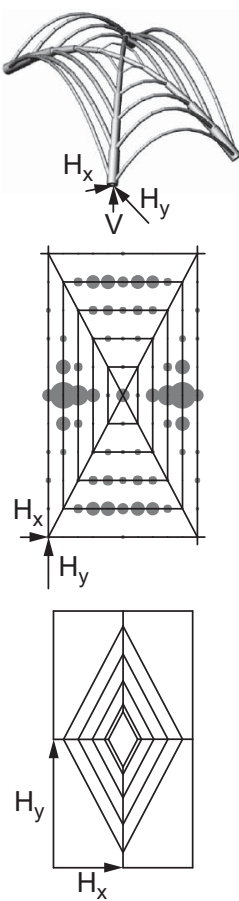

(a)
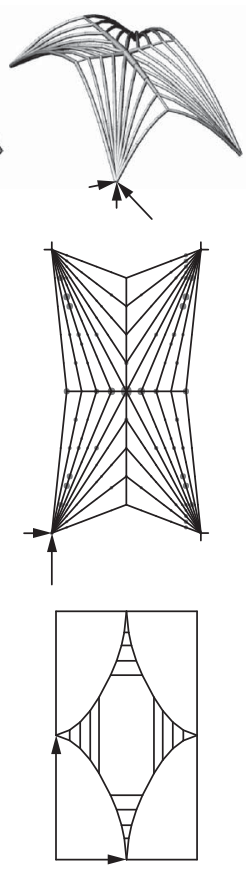

(b)
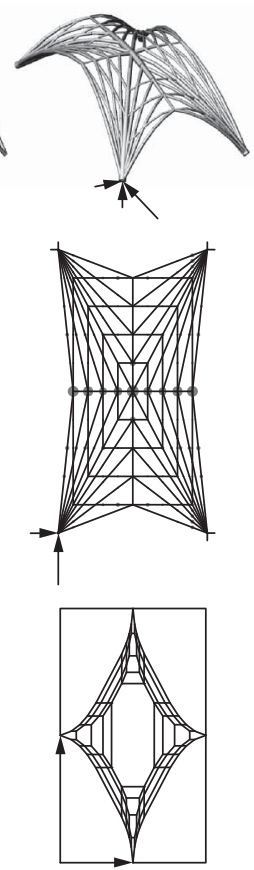

(c)
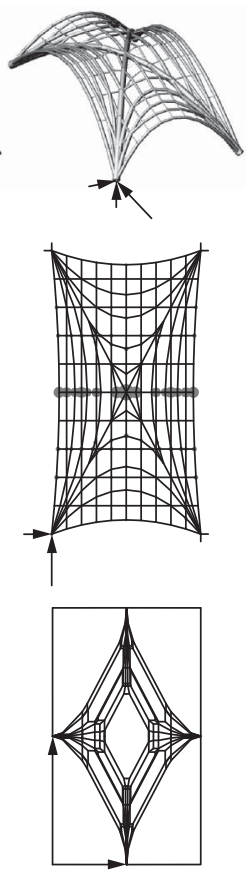

(d)
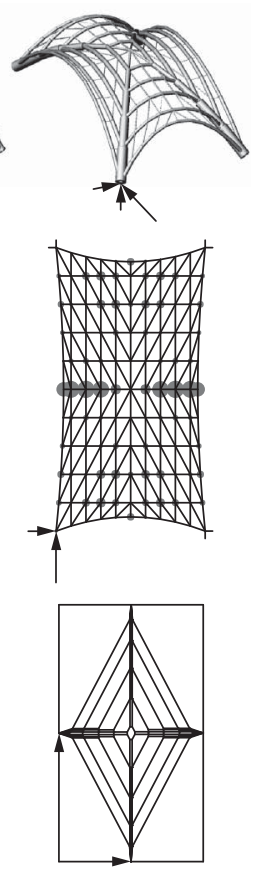

(e)

Figure 8. Illustration of results. Top row: Resulting best-fit thrust networks to the target surface, chosen as the mid surface of the vault geometry in Figure 7, with pipes around its edges proportional to the magnitude of force in them. Center row: Form diagrams: (a) parallel arches and rib arches; (b) fan-like arrangement of arches directly going to the corner supports; (c) superposition of the first two patterns; (d) pattern combining a regular quadrilateral grid with arches in plan to the supports; and (e) triangulated pattern with its diagonals oriented towards the corners. The circles over each node are proportional to the vertical deviation of the node in the solution. Bottom row: Reciprocal force diagrams, corresponding to the respective best-fit solutions for the five patterns and drawn to the same scale.

Pattern (a) assumes parallel web arches, supported by diagonal rib arches, carrying the loads to the supports; in (b), arches are laid out in plan in a fan-like arrangement from the supports, connected at the ridges; pattern (c) is a superposition of the first two patterns, thus combining both load-carrying logics; pattern (d) combines a regular quadrilateral grid with arches in plan, which run to the supports; and pattern (e) was proposed in O'Dwyer (1999) to be a good pattern to represent the combined force flow logics of patterns (a) and (b), thus in intent equivalent to pattern (c), but not a direct superposition.

For each network topology, the least-squares best-fit solution to the center surface of the vault geometry in Figure 7 is compared, considering the self-weight of the vault only, so without taking into account the typical fill over the vault's haunches. Table 1 shows the summary of the results obtained with the best-fit solving algorithm for the different force patterns in Figure 8 with $m$, the number of edges of the network; $n_{i}$, the number of free nodes, i.e. the number of nodes that have a to-be-found height; $k$, the number of degrees of structural indeterminacy of the network, i.e. the amount of independently chosen force densities, which is dependent on the pattern's topology and geometry and represents its complexity (Block and Lachauer 2011); the global, averaged fitness measure of the 
Table 1. Summary of the results obtained with the best-fit solving for the five patterns (a-e) in Figure 8

\begin{tabular}{lcccccc}
\hline Pattern & $m$ & $n_{i}$ & $k$ & $f / n_{i}\left[\mathrm{~mm}^{2}\right]$ & $\left|z-z^{\mathrm{M}}\right|_{\max }[\mathrm{mm}]$ & $\left|z-z^{\mathrm{M}}\right|$ mean $[\mathrm{mm}]$ \\
\hline $\mathrm{a}$ & 148 & 121 & 10 & 1778 & 142 & 29 \\
$\mathrm{~b}$ & 252 & 213 & 18 & 242 & 54 & 12 \\
$\mathrm{c}$ & 380 & 261 & 34 & 187 & 62 & 13 \\
$\mathrm{~d}$ & 480 & 225 & 36 & 337 & 84 & 10 \\
$\mathrm{e}$ & 328 & 121 & 86 & 1068 & 93 & 24 \\
\hline
\end{tabular}

solution, $f / n_{i}$, which is the cost divided by the number of free nodes; and the maximum and average vertical deviations in absolute values of the nodes of the thrust network from the target surface along the mid surface of the vault, $\left|z-z^{\mathrm{M}}\right|_{\max }$ and $\left|z-z^{\mathrm{M}}\right|_{\text {mean }}$.

Comparing the average cost per node, $f / n_{i}$, it is not surprising that pattern (a) performs the worst, as the simple arches running across the web of the vault will have approximately catenary shapes and thus never fit a pointed arch section well. A remarkable improvement is observed for pattern (b). Indeed, this fan-like arrangement is connected at the vault's ridges, allowing for a "kink", both in plan and in elevation, in the funicular arches crossing the vault's web. The best solution, considering the least-squares objective, is achieved with the superposed pattern (c), although the improvement over (b) is not that significant. This result is at first sight surprising, but can be explained after comparing their respective reciprocal diagrams: indeed the reciprocal diagram of pattern (c) has globally a very similar thrust distribution as pattern (b), showing that the parallel arches of pattern (a) only provide a minimal contribution. Pattern (d) does not perform better, which can be explained by the remaining arch sections in the pattern that run perpendicular to and over the pointed ridges of the singly curved web sections, indeed causing the largest deflections along that line. If this issue would be addressed, for example with a strategy as used in pattern (b), then this pattern would perform the best with respect to the chosen objective, as can be seen by the best score in the average deflection $\left|z-z^{\mathrm{M}}\right|_{\text {mean }}$. Pattern (e), even though triangulated, and hence having the most degrees of indeterminacy, thus the most options to redistribute the horizontal thrusts, performs very poorly. The resulting values are similar, although slightly better, to those obtained with pattern (a). Observing that their reciprocal diagrams have very similar layouts, the reason for these similar results can be explained: even though triangulated with edges orientated globally towards the supports, the pattern has no "arches" in plan that can collect the web thrusts directly into the supports. Because of this, the network is basically reduced to parallel arches spanning the web, with minimal forces in the connecting, transverse edges. So, O'Dwyer's suggestion that this would be a good pattern to represent the vault's flow of forces does not work for supports only at the corners. This of course happens because the form diagram is kept fixed during the analysis.

As a general remark, it is interesting that although the diagrams show that for each solution the thrusts are redistributed very differently inside of the vault, the horizontal thrust in $\mathrm{x}$ - and $\mathrm{y}$-direction at the corner supports differ by less than $5 \%$, as can be seen by the overall similar sizes of the force diagrams, suggesting that a top-level equilibrium analysis would have sufficed, a result which Holzer (2012) showed based on the typically recurring crack patterns for quadripartite vaults observed in practice. Indeed, global equilibrium should be satisfied, so it is in this context important to point out that the presented fully 3D approach has most advantage over pseudo-3D analyses when indeed the chance to redistribute and explicitly control the thrusts is fully exploited. Much less conservative results 
can be obtained in critical points with patterns that do not necessarily all go to the corner supports, but allow some thrust to be taken by neighboring elements, such as adjoining vaults or sidewalls. A particularly interesting potential of the method is that these thrusts can be directly and explicitly constrained to particular values, which, for example, are defined by the lateral stability or different stiffness's of these abutments (see Section 5).

Note also that the least-squares objective, fitting the vault's mid surface, does not necessarily result in the solution with the highest geometric safety factor (GSF), but rather provides a lower-bound on it. To obtain the real GSF, one would need to minimize $\left|z-z^{\mathrm{M}}\right|_{\max }$ instead. Nonetheless, these theoretical findings add a new contribution to the historic discussion, and provide new arguments and insights to come closer to understanding the structural behavior of masonry cross vaults. Regardless of the above discussion, it is important to remember that all of these solutions represent admissible distributions of stress for the vault's geometry, if no cracks or other structural pathologies exist. None of these necessarily represent the "real" equilibrium state of the vault; this one, we will never know due to, for example, the unknowable support and material properties of historic masonry (Heyman 1995; Huerta 2008).

\subsection{Rose Windows}

The delicate stone tracery of large rose windows provides an additional challenge for $3 \mathrm{D}$ analysis of masonry structures. The stability of these daring masonry structures have not been studied much (Heyman, 2002; Clifton and Willis, 2007; Block, 2009; Caprili, RoyerCarfagni, and Salvatore 2011). The main loading of large windows of Gothic churches and cathedrals is the pressure and suction caused by wind. Assessing their out-of-plane stability is therefore crucial. In order to withstand these lateral loads, these window structures have to develop flat-arch action in their shallow depth (Heyman, 2002). The structural action of rose windows is similar to flat circular vaults, but they differ in that the force paths are defined and limited by the layout of the ribs of the window tracery.

4.2.1. Notre Dame de Mantes, France This section first focuses on a rose window with a statically determinate form diagram, with three bars coming together at each intersection, resulting in a force diagram consisting of only triangles. This means that all forces in the system are known up to a scale, which is defined by the loading and the depth of the mullions. Neglecting the contribution of the self-weight of the window, this means that the same reaction force is required from all sides. Because of the simple, statically determinate geometry, these conclusions could of course also have been made using simple trigonometry and hand calculations, as done in Heyman (2002).

TNA can be used to model the flat vault action of the rose window of the Notre Dame de Nantes, or Mantes-la-Jolie Cathedral, France, originally constructed circa 1180. Figure 9 shows (a) the assumed form diagram, which approximates the structure as a bar-node system; and (b) the unique corresponding force diagram, drawn to scale. The grey dotted lines in Figure 9a contour the tributary areas of the loaded nodes, found using Voronoi diagrams on the vertical plane of the window as the wind loading is the dominant loading to be considered. The corresponding compressive equilibrium solution in Figure 9c visualizes the flat-vault action of the structure. The thrust network is in equilibrium with the wind loads and stays within the depth of the mullion structure.

The obtained solution is compared with Heyman's (2002) results. Using this fully 3D approach, for the same geometry (diameter of the rose window is $8 \mathrm{~m}$ and mullions of $25 \mathrm{~cm}$ 


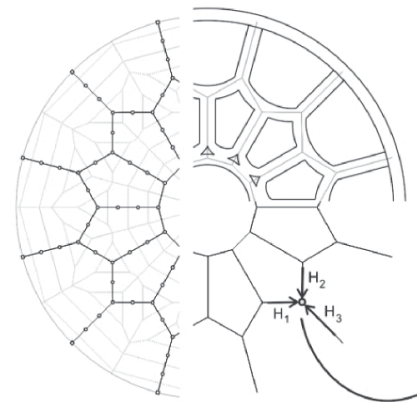

(a)

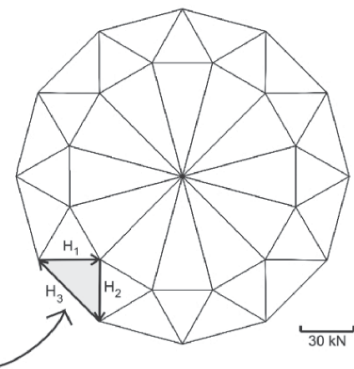

(b)

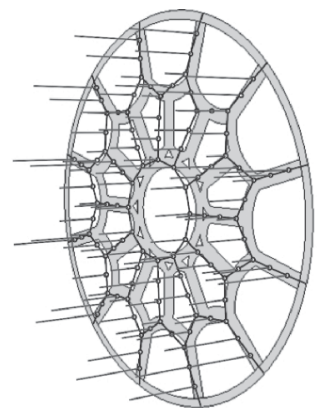

(c)

Figure 9. Illustration of thrust network analysis of the rose window of Notre Dame de Mantes, France: (a) the structural action is reduced to a bar-node system (after Heyman 2002); (b) the in-plane forces in the rose window due to the wind loading can be measured from the reciprocal force diagram; (c) the equilibrium network demonstrates flat-vault action.

by $25 \mathrm{~cm})$ and wind loading $\left(2 \mathrm{kN} / \mathrm{m}^{2}\right)$, the minimum thrust of the final spokes is $49.6 \mathrm{kN}$. Heyman used a simplified two-dimensional approach to determine a value of $67 \mathrm{kN}$, which is $35 \%$ higher, and hence more conservative. For this case, TNA provides thus a significant improvement over existing hand methods of analysis, only by having a 3D thrust network.

Because the joints between the stones making up the mullions are parallel to the dominant wind loading and the proportion of the cross-sectional area of the mullions compared to the loaded area is small, this failure mode can be critical and sliding due to the shear forces needs to be checked at the interfaces of the outer spokes with the outer ring. To prevent this failure, iron connecting dowels were often inserted to transfer the shear forces (Heyman 2002; Clifton and Willis 2007).

The obtained flat-vault action causes stresses less than $800 \mathrm{kN} / \mathrm{m}^{2}$, which is more than an order of magnitude below the crushing strength of even the softest limestone $\left(12,000 \mathrm{kN} / \mathrm{m}^{2}\right)$. This result needs to be considered carefully though, since the analysis assumed that the window has a perfect geometry that can generate the suggested minimum thrust flat vault action. For even small out-of-plane deflections of the window, which is not unthinkable for large area windows, the thrust network, constrained by the formation of hinges in the mullions and the decreased height due to the resulting "sagging" mechanism of the window, quickly becomes nearly flat, resulting in very high thrust values and hence high stresses on reduced sections. This makes rose windows candidates where not only the geometry and stability, but also elasticity and interface material properties have an important impact on their stability because of the potential for snap-through failures of the slender ribs or shearing failure at their interfaces.

This example only attempted at improving Heyman's results (2002) through a fully $3 \mathrm{D}$ equilibrium network. Proper analysis would again demand a careful assessment of the structural pathologies, an investigation in the construction technique and process, and a general investigation of the conservation state.

4.2.2. Intricate Mullion Geometries The result of the 3D assessment in Section 4.2.1 shows that significant improvements over pseudo-3D approaches can be obtained just by considering the problem, using exactly the same assumptions, in three dimensions. Most 
rose windows do not have such simple and structurally determinate layouts as the rose window of the Notre Dame de Mantes though (Figure 10a). More complex rose window geometries, such as shown in Figures 10b-10f, cause two challenges to the analyst: first, because several intersections have more than three ribs coming together, thrusts can be equilibrated in different manners in those nodes; and second, because the many three-valent intersections, the central axis lines of the mullions are not necessarily possible geometries that can be in equilibrium in compression (Block 2009). This issue can be explained with the triangulated reciprocal force diagram in Figure 9b, which can only be composed out of closed force vector polygons in a single, unique way. The corresponding edges between form and force diagram need to be parallel, so an equilibrated network does not necessarily coincide perfectly with the centerlines of the windows' ribs.

The first issue is of course one of the key aspects that the method demonstrated in this paper addresses, but the second issue demands a special approach. In contrast to the example of the continuous groin vault in Section 4.1, rose windows can only transfer significant compression forces through their mullions. As mentioned above, the networks, obtained by tracing these, do not necessarily result in a geometry that represents an equilibrium solution, which thus also means that the thrusts in the ribs could not even be found with trigonometry or equations, as global equilibrium would not be possible, which would correspond to a reciprocal force diagram that cannot be closed. Therefore, a form diagram needs to be found that aligns as close as possible to the centerlines of the mullions, but for sure stays within their width. For this, an iterative solving procedure has been used that enforces equilibrium in the form diagram by explicitly using the information of the connected force diagram (Rippmann et al., 2012a). This approach could be considered as a relaxation procedure, and is available as part of the free plug-in RhinoVAULT (Rippmann et al., 2012b). This preparatory step was needed to generate proper form diagrams for most of the rose windows shown in Figure 10.

\subsection{Gothic Vault With Complex Rib Geometry}

This section looks at the equilibrium of the nave vaults of Sherborne Abbey in Dorset, England, finished circa 1490 (Figure 11a). These beautiful vaults, with a main span of $12 \mathrm{~m}$, are a crossing between lierne and fan vaults. From plans and sections, complemented with information obtained from photographs, a simplified 3D model was made of the vaults (Figure 11b). The main features of the vault, the beautiful rib pattern, then served as guide to draw a force pattern (Figure 12a).

The form diagram in Figure 12a has 949 edges and 462 nodes. The problem could be reduced to 183 variables, which was obtained with the matrix analysis developed for the first, algebraic solving algorithm discussed in Section 3.1, showing that this is a statically highly indeterminate problem. The resulting best-fit thrust network in Figure 12c was found in only 4 seconds with the second solving strategy discussed in Section 3.1, showing that intricate network topologies, and complex vault geometries, can be solved efficiently and that the solving algorithms are robust, even for large problems. This result is not a virtue by itself, but shows that the solvers are fast, even for such large networks, demonstrating that many different assumptions can be checked easily, which, for example, with thrust line analysis is absolutely not possible, as it demands very tedious constructions and a lot of intuition and experience to assume how the different two-dimensional force lines would interact in three dimensions. 
(a)

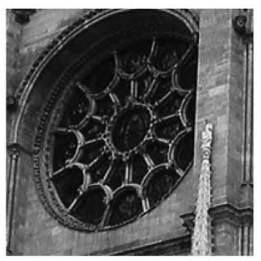

(b)

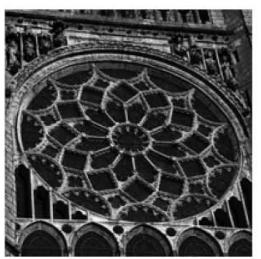

(c)

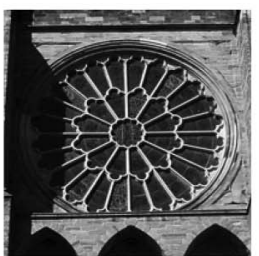

(d)

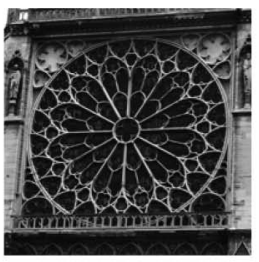

(e)

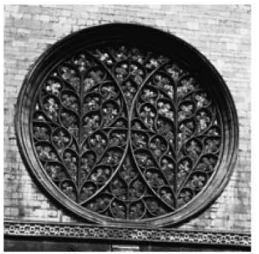

(f)

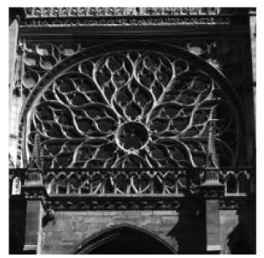

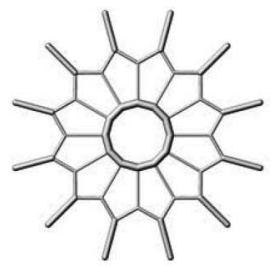
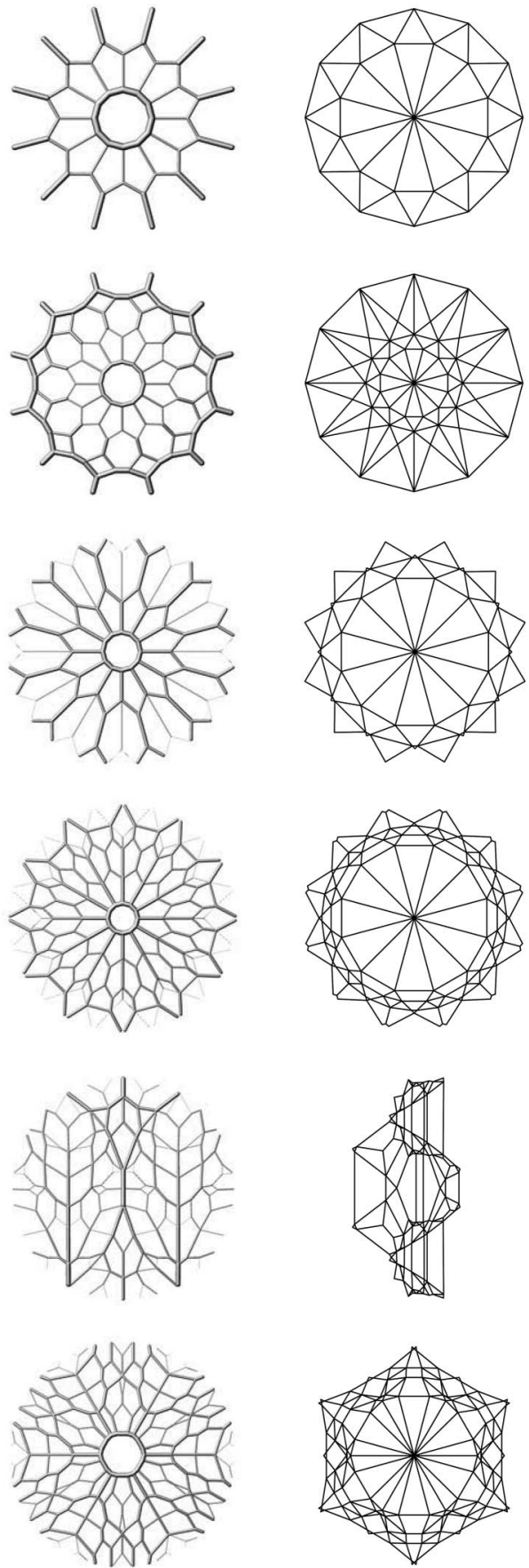

Figure 10. Photographs and diagrams of different rose windows with complex mullion geometries, showing from left to right an outside picture, the equilibrated and piped form diagram, and the reciprocal force diagram: (a) Notre Dame de Mantes, France; (b) Notre Dame de Chartres, France (Photo by Holly Hayes); (c) Durham Cathedral, England (Photo by Carcharoth on Wikipedia); (d) Notre Dame de Paris, France (Photo by Ellen Brown); (e) Bisshop's Eye of Lincoln Cathedral, England (Photo from Cornell University Library); (f) Sainte-Chapelle Paris, France. 

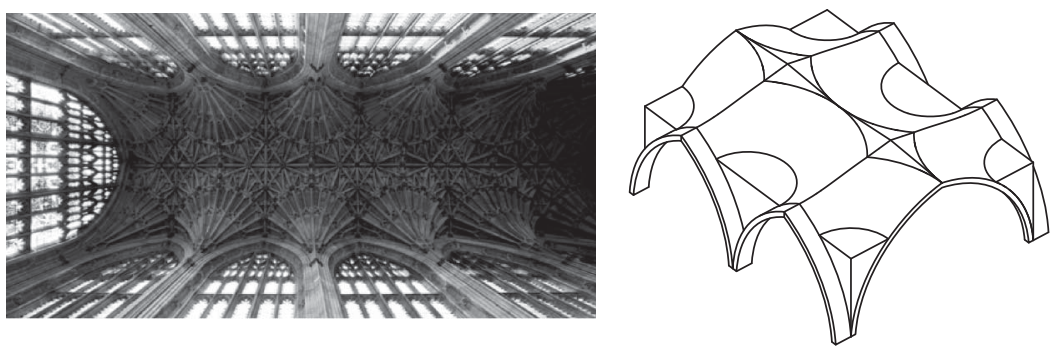

Figure 11. Photograph (by Lawrence Lew) and simplified 3D model of the geometry of the Nave Vaults of the Sherborne Abby, Dorset, England.

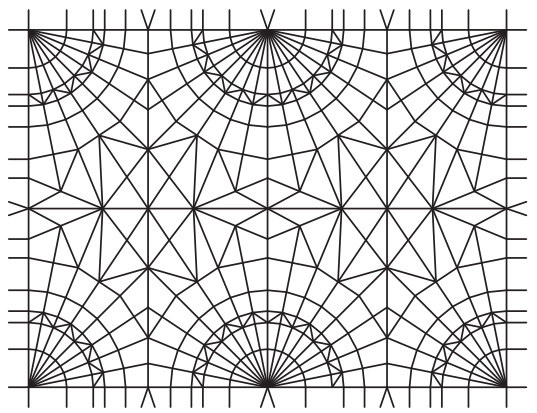

(a)

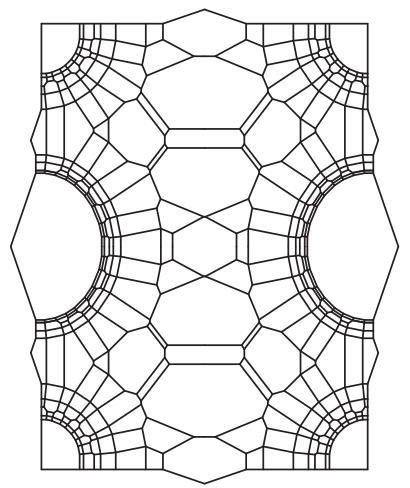

(b)

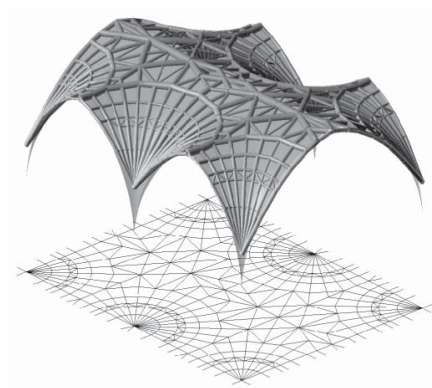

(c)

Figure 12. Illustrations of (a) the form diagram, directly using the rib layout of the vaults, (b) the resulting best-fit reciprocal force diagram, and (c) the target surface and piped best-fit solution for Sherborne Abbey's nave vaults.

Because the purpose of this example was to show the potential of the implementation, the calculation of the weight has been simplified by taking a vault of uniform thickness. In reality though, the vaults have varying thicknesses due to the different extrados geometry than the intrados', as can be assumed from the drawings of the extrados of the choir vaults of the same church by Acland (1972). Also, the haunch fill has not been included. Regardless of these strong assumptions, the thrust network still fits the mid surface remarkably well. The main vertical deviations occur at mid span and where the fill is located, with an amount of $2.8 \%$ and $3.1 \%$ of the span respectively. Expecting a thickened section at mid span in reality (Acland, 1972) and significant haunch fill, these results could thus be improved 
significantly by using the correct weights as input. These results again demonstrate the absolutely sensational expertise and knowledge of the Gothic master builders, who built these beautiful masterpieces well before any structural theory was in place.

\section{DISCUSSION AND FUTURE WORK}

As shown through a series of example applications, 3D thrust network analysis can be used to improve the understanding of masonry vaults with complex geometry. Especially the speed of finding different equilibrium solutions for very sophisticated vaults makes the approach appropriate and useful for practical applications, where time and budget constraints often do not permit the time-intensive modeling and analyzing of nonlinear finite element or discrete element models. The input is furthermore very straightforward, and allows the analyst to easily incorporate singularities in loading (point loads), boundary conditions (non-properly supported edges), and equilibrium solution (cracks and hinges). The visual and intuitive control and feedback of the presented method furthermore make its results easy to interpret. All these aspects are key advantages for practical applications.

Compared with simplified equilibrium analysis, such as global equilibrium checks, combined thrust line analysis to do a pseudo-3D analysis, or shell aprroximations, this flexible approach allows to redistribute thrusts in an optimization problem such that fully $3 \mathrm{D}$ solutions can reduce the critical thrust values. The approach is readily usable for new masonry vaulting with perfect, non-cracked geometry and controlled supports, but further research and development is needed though to be able to address all challenges needed to be able to assess real, non-perfect historical construction in masonry.

The examples in Sections 4.1 illustrated that the outcome of the method strongly depends on the layout (topology and geometry) of the form diagram. Even though results can be generated fast, a general strategy for generating appropriate form diagrams would be very useful. These typically depend on the intuition of the structural analyst, and as discussed, curvature analysis does not suffice. A solution for this has been provided by Panozzo et al. (2013) though. Less ideal layouts result in bad approximations of the geometry, sometimes cause instabilities in the nonlinear solver, or are just infeasible, i.e. it is impossible to find a compression-only equilibrium solution for the provided pattern. Some of these issues can be solved with the more robust relaxation strategies presented, but these come at the cost of control. A general strategy for the generation of form diagrams would take into account the global vault geometry (for example, force lines are needed were creases occur in the geometry), the loading case, as well as properties of the measured construction geometry, including the vault's stereotomy or observed structural pathologies, such as cracks, hinge lines or holes.

In order to make meaningful statements on the stability and load capacity of vaulted masonry structures, it will be important to build upon this research to include other optimization objectives such as finding the minimum and maximum thrust states and the collapse load and geometric safety factors, but also for example a global tilt test, which is a parallel loading case and can thus be done with the thrust network analysis framework, to obtain an upper bound on the stability of a structure under horizontal forces, such as from a seismic event (Block et al. 2006b).

Future research will also address the integration of bounds on solutions, e.g. to limit the thrusts to the lateral stability capacity of abutments (see Section 4.1); the imposing of hard constraints, e.g. to constrain equilibrium solutions to pass through observed hinge lines; the addition of the thrust zone concept (Smith et al. 1990), which again could be 
achieved effectively by putting constraints on the nodal heights in combination to the thrust values, known from the reciprocal force diagram; and the extension to non-parallel loads.

Lastly, an important aim for future research is to examine if, as in two-dimensional arch analysis (Heyman 1995; Ochsendorf 2002), these thrust networks can provide information about possible collapse mechanisms for fully 3D problems. An exhaustive analysis should thus run through all the possible variations in force patterns and internal force distributions to identify the critical equilibrium states. This asks for an additional optimization procedure, which combines the algorithms demonstrated in this paper with a search over all force pattern topologies, but also the implementation of the minimum versus maximum thrust or collapse load objectives.

\section{CONCLUSION}

This study showed through examples that the new robust and efficient solving algorithms developed to extend the Thrust Network Analysis framework allow to find best-fit thrust networks for masonry vaults with complex geometries. These solutions give good lower bounds on the geometric safety factors of these structures. The presented implementations can be seen as a sketch for a practical, fully 3D implementation for equilibrium analysis of vaulted masonry.

The prototype implementation allowed discussing the force flow in cross vaults with perfect geometry using objective metrics; giving new insights into the thrust equilibrium of the flat-vault action of several rose windows with interesting mullion geometries; and showing the careful distribution of thrusts that results in a thrust network, equilibrated in compression, that traces intricate rib geometries.

\section{ACKNOWLEDGMENT}

The first author is thankful for the discussions with Prof. John Ochsendorf on the case studies in Sections 4.1 and 4.2.1 during his doctoral studies at MIT.

\section{REFERENCES}

Abraham, P. 1934. Viollet-le-Duc et le Rationalisme Médiéval. Paris, France: Fréal \& Cie.

Acland, J. H. 1972. Medieval structure: The Gothic vault. Toronto, Canada: University of Toronto Press.

Andreu, A., Gil, L., and Roca, P. 2007. Computational analysis of masonry structures with a funicular model. Journal of Engineering Mechanics 133(4): 473-480.

Andreu, A., Gil, L., and Roca, P. 2010. Analysis of masonry structures by funicular networks. Proceedings of the ICE -Engineering and Computational Mechanics 163(3): 147-154.

Barthel, R. 1994. Tragverhalten gemauerter Kreuzgewölbe. In Aus Forschung und Lehre 34. Karlsruhe, Germany: Institut für Tragkonstruktionen.

Block, P. 2009. Thrust network analysis: Exploring three-dimensional equilibrium. Doctoral Dissertation Massachusetts Institute of Technology, Cambridge, MA.

Block, P., Ciblac, T., and Ochsendorf, J. A. 2006a. Real-time limit analysis of vaulted masonry buildings. Computers \& Structures 84(29-30): 1841-1852.

Block, P., DeJong, M., and Ochsendorf, J. 2006b. As hangs the flexible line: Equilibrium of Masonry Arches. Nexus Network Journal 8(2): 9-19.

Block, P., and Ochsendorf, J. 2007. Thrust network analysis: A new methodology for threedimensional equilibrium. Journal of the IASS 48(3): 167-173. 
Block, P., and Ochsendorf, J. 2008. Lower-bound analysis of masonry vaults. In Proceedings of the $6^{\text {th }}$ International Conference on Structural Analysis of Historic Construction. Bath, UK, 593-600.

Block, P., and Lachauer, L. 2011. Closest-fit, compression-only solutions for free-form shells. In Proceedings of the IABSE-IASS Symposium, London, UK.

Boothby, T. E. 2001. Analysis of masonry arches and vaults. Progress in Structural Engineering and Materials 3(3): 246-256.

Calladine, C. R. 1983. Theory of shell structures. Cambridge, MA: Cambridge University Press.

Caprili, S., Royer-Carfagni, G., and Salvatore, W. 2011. Rose windows: Daring slender structures. In Proceedings of AIMETA 2011, Bologna, Italy.

Clifton, G., and Willis, G. 2007. Dean's eye window: The reconstruction of a medieval rose window at Lincoln Cathedral. Structural Engineer 85(3): 40-46.

Durand-Claye, A. 1867. Note sur la vérification de la stabilité des voûtes en maçonnerie et sur l'emploi des courbes de pression. Annales des Ponts et Chausses 1: 63-96.

Durand-Claye, A. 1880. Vérification de la stabilité des voûtes et des arcs. Application aux voûtes spheriques. Annales des Ponts et Chausses 1: 416-440.

Fitchen, J. 1961. The Construction of Gothic Cathedrals-A study of medieval vault erection. Chicago, IL: University of Chicago Press.

Fraternali, F. 2010. A thrust network approach to the equilibrium problem of unreinforced masonry vaults via polyhedral stress functions. Mechanics Research Communications 37(2): 198-204.

Fraternali, F., Angelillo, M., and Fortunato, A. 2002. A lumped stress method for plane elastic problems and the discrete-continuum approximation. International Journal of Solids and Structures 39(25): 6211-6240.

Fraternali, F., and Rocchetta, G. 2002. Shape optimization of masonry vaults. In Proceedings of the $2^{\text {nd }}$ International Conference on Advances in Structural Engineering and Mechanics, Busan, South Korea.

Heyman, J. 1966. The stone skeleton. International Journal of Solids and Structures 2(2): 249-279.

Heyman, J. 1968. On the rubble vaults of the middle ages and other matters. Gazette des Beaux-Arts 71: 177-188.

Heyman, J. 1977. Equilibrium of shell structures. Oxford, UK: Clarendon Press.

Heyman, J. 1982. The masonry arch. Chichester, UK: Ellis Horwood.

Heyman, J. 1995. The stone skeleton: Structural engineering of masonry architecture. Cambridge, UK: Cambridge University Press.

Heyman, J. 2002. Rose windows. In New Approaches to structural mechanics, shells and biological structures, eds., H. R. Drew and S. Pellegrino. Dordrecht, The Netherlands: Kluwer Academic Publishers.

Holzer, S. M. 2012. Numerical arch and vault analysis. In Proceedings of the $8^{\text {th }}$ International Conference on Structural Analysis of Historic Construction. Wroclaw, Poland, 77-93.

Huerta, S. 2001. Mechanics of masonry vaults: The equilibrium approach. In Proceedings of Historical Constructions, Guimaraes, Portugal, 47-69.

Huerta, S. 2004. Arcos bóvedas y cúpulas. Geometría y equilibrio en el cálculo tradicional de estructuras de fábrica. Madrid, Spain: Instituto Juan de Herrera.

Huerta, S. 2008. The analysis of masonry architecture: A historical approach. Architectural Science Review 51(4): 297-328.

Jagfeld, M., and Barthel, R. 2004. Zur Gelenkbildung in historischen Tragsystemen aus Mauerwerk. Bautechnik 81(2): 96-102.

Kooharian, A. 1952. Limit analysis of voussoir (segmental) and concrete arches. Journal American Concrete Institute 49(12): 317-328.

Kurrer, K.-E. 2008. The history of the theory of structures. From arch analysis to computational mechanics. Berlin, Germany: Ernst \& Sohn.

Mark, R., Abel, J. F., and O'Neill, K. 1973. Photoelastic and finite-element analysis of a quadripartite vault. Experimental Mechanics 13(8): 322-329. 
Maxwell, J.C. 1864. On reciprocal figures and diagrams of forces. Philosophical Magazine and Journal Series, 4(27): 250-261.

Ochsendorf, J.A. 2002. Collapse of masonry structures. Doctoral Dissertation University of Cambridge, Cambridge, UK.

O'Dwyer, D.W. 1999. Funicular analysis of masonry vaults. Computers \& Structures 73(1-5): 187-197.

Panozzo, D., Block, P., and Sorkine-Hornung O. 2013. Designing unreinforced masonry models. ACM Transactions on Graphics (Proceedings of ACM SIGGRAPH) 32(4): 91:1-91:2.

Pellegrino, S., and Calladine, C.R. 1986. Matrix analysis of statically and kinematically indeterminate frameworks. International Journal of Solids and Structures 22(4): 409-428.

Rave, W. 1939. Über die Statik mittelalterlicher Gewölbe. Deutsche Kunst-und Denkmalpflege 1939/ 1940: 193-198.

Rippmann, M., Lachauer, L., and Block, P. 2012a. Interactive vault design. International Journal of Space Structures 27(4): 219-230.

Rippmann, M., Lachauer, L., and Block, P. 2012b. RhinoVAULT: Funicular form finding of shells [computer software]. http://block.arch.ethz.ch/tools/rhinovault (accessed August 28, 2013)

Roca, P., Cervera, M., Gariup, G., and Pela, L. 2010. Structural Analysis of Masonry Historical Constructions. Classical and Advanced Approaches. Archives of Computational Methods in Engineering 17(3): 299-325.

Sabouret, V. 1928. Les vôutes d'arrètes nervures. Rôle simplement décoratif des nervures. Le Génie Civil 92: 205-209.

Schek, H.-J. 1974. The force density method for form finding and computation of general networks. Computer Methods in Applied Mechanics and Engineering 3(1): 115-134.

Smith, F. W., Harvey, W. J., and Vardy, A. E. 1990. Three-hinge analysis of masonry arches. Structural Engineer 68(11): 203-213.

Ungewitter, G. 1890. Lehrbuch der gotischen Konstruktionen (3rd ed.), ed., K. Mohrmann. Leipzig, Germany: T.O. Weigel Nachfolger.

Van Mele, T., Lachauer, L., Rippmann, M., and Block, P. 2012. Geometry-based understanding of structures. Journal of the IASS 53(4): 285-295.

Van Mele, T., D. Panozzo, O. Sorkine-Hornung, and P. Block. 2014. Best-fit thrust network analysis. In Shell for Architecture: Form finding and structures optimization, eds., S. Adriaenssens, P. Block, D. Veenendaal, and C. J. K. Williams. London, UK: Routledge.

Viollet-le Duc, E. E. 1854-1868. Dictionnaire raisonné de l'architecture française du XIe au XVIe siècle, vol. 2: Construction. Paris, France: B. Bance.

Vouga, E., Höbinger, M., Wallner, J., and Pottmann, H. 2012. Design of self-supporting Surfaces. ACM Transactions on Graphics-SIGGRAPH 2012 Conference Proceedings 31(4): Art. 87.

Wittmann, W. 1879. Zur Theorie der Gewölbe. Zeitschrift für Bauwesen 26: 61-74.

Wolfe, W. S. 1921. Graphical analysis: A handbook on graphic statics. New York, NY: McGraw-Hill Book Company. 